\title{
Equine CTNNB I and PECAMI nucleotide structure and expression analyses in an experimental model of normal and pathological wound repair
}

\author{
Vincenzo Miragliotta $^{\dagger 2}$, Zoë Ipiña ${ }^{\dagger 1}$, Josiane Lefebvre-Lavoie ${ }^{1}$, \\ Jacques G Lussier ${ }^{1}$ and Christine L Theoret*1
}

\begin{abstract}
Address: ${ }^{1}$ Département de biomédecine vétérinaire, Faculté de médecine vétérinaire, Université de Montréal, C.P. 5000, St-Hyacinthe, Québec, J2S 7C6, Canada and 2Department of veterinary anatomy, biochemistry and physiology, University of Pisa, Viale delle Piagge 256100 Pisa, Italy

Email: Vincenzo Miragliotta - vincenzo.miragliotta@vet.unipi.it; Zoë Ipiña - zoeip@ hotmail.com; Josiane Lefebvre-Lavoie - josiane.lefebvrelavoie@umontreal.ca; Jacques G Lussier - jacques.lussier@umontreal.ca; Christine L Theoret* - christine.theoret@umontreal.ca

* Corresponding author †Equal contributors
\end{abstract}

Published: 3I January 2008

BMC Physiology 2008, 8:1 doi:10.1186/1472-6793-8-I

This article is available from: http://www.biomedcentral.com//472-6793/8/I

(c) 2008 Miragliotta et al; licensee BioMed Central Ltd.

This is an Open Access article distributed under the terms of the Creative Commons Attribution License (http://creativecommons.org/licenses/by/2.0), which permits unrestricted use, distribution, and reproduction in any medium, provided the original work is properly cited.

\begin{abstract}
Background: Wound healing in horses is fraught with complications. Specifically, wounds on horse limbs often develop exuberant granulation tissue which behaves clinically like a benign tumor and resembles the human keloid in that the evolving scar is trapped in the proliferative phase of repair, leading to fibrosis. Clues gained from the study of over-scarring in horses should eventually lead to new insights into how to prevent unwanted scar formation in humans. cDNA fragments corresponding to CTNNBI (coding for $\beta$-catenin) and PECAMI, genes potentially contributing to the proliferative phase of repair, were previously identified in a mRNA expression study as being up-regulated in 7 day wound biopsies from horses. The aim of the present study was to clone fulllength equine CTNNBI and PECAMI CDNAs and to study the spatio-temporal expression of $m R N A s$ and corresponding proteins during repair of body and limb wounds in a horse model.
\end{abstract}

Results: The temporal pattern of the two genes was similar; except for CTNNBI in limb wounds, wounding caused up-regulation of mRNA which did not return to baseline by the end of the study. Relative over-expression of both CTNNBI and PECAMI mRNA was noted in body wounds compared to limb wounds. Immunostaining for both $\beta$-catenin and PECAMI was principally observed in endothelial cells and fibroblasts and was especially pronounced in wounds having developed exuberant granulation tissue.

Conclusion: This study is the first to characterize equine cDNA for CTNNBI and PECAMI and to document that these genes are expressed during wound repair in horses. It appears that $\beta$-catenin may be regulated in a post-transcriptional manner while PECAMI might help thoracic wounds mount an efficient inflammatory response in contrast to what is observed in limb wounds. Furthermore, data from this study suggest that $\beta$-catenin and PECAMI might interact to modulate endothelial cell and fibroblast proliferation during wound repair in the horse. 


\section{Background}

Repair of wounds located on the limbs, but not the body, of horses is often accompanied by the formation of exuberant granulation tissue (EGT) which behaves clinically like a benign tumor and resembles the human keloid $[1,2]$ in that the evolving scar is trapped in the proliferative phase of repair, leading to fibrosis. This condition ultimately generates extensive scarring, detrimental to function. Indeed, a recent study reported that approximately $7 \%$ of injuries leading to the retirement of racehorses are the result of a wound [3]. Efforts to enhance wound repair and to prevent unwanted scar formation in both humans and horses have been disappointing, possibly owing to insufficient knowledge of the underlying mechanisms.

We recently identified genes expressed in wound margin biopsies of horses, using suppression subtractive hybridization (SSH) [4]. Two hundred and twenty six cDNAs were found to be differentially expressed during the proliferative phase of repair of normal body wounds, 129 of which matched against GenBank databases. In the study described herein, we targeted a previously identified SSHderived cDNA fragment corresponding to $\beta$-catenin (CTNNB1) and a second corresponding to equine platelet endothelial adhesion molecule-1 (PECAM1) for their potential contribution to the proliferative phase of repair, which is aberrant following wounding on the limbs of horses. CTNNB1 had already been demonstrated to play a role in fibroproliferative disorders $[5,6]$ and PECAM1 was chosen because of its known interaction with $\beta$-catenin [7].

Beta-catenin is an $88-\mathrm{kDa}$ highly conserved protein that is a structural component of the adherens junction (AJ), a cadherin-dependent adhesive structure intricately linked to the actin microfilament network and located between adjacent epithelial cells. Beta-catenin is a central mediator in the canonical wingless (Wnt) signaling pathway, which exerts remarkable control over cellular phenotype and behavior [8]. When the Wnt pathway is quiescent, $\beta$-catenin participates in AJs which must disassemble to allow for cell migration, a process critical to epithelialization following wounding. When freed from intercellular contacts, $\beta$-catenin is phosphorylated and targeted for degradation [6]. Activation of the Wnt pathway inhibits phosphorylation, leading to cytosolic stabilization of $\beta$ catenin. This stabilized form subsequently translocates to the nucleus where it functions as a transcriptional co-activator of $\mathrm{T}$ cell factor/lymphoid enhancer factor (Tcf/Lef) target genes [9].

Beta-catenin plays a cell-specific role during wound repair. Protein levels are transiently elevated in mesenchymal cells during the proliferative phase of repair [5], which is thought to regulate the growth of dermal fibrob- lasts $[10,11]$. Moreover, $\beta$-catenin stimulates the growth of microvascular endothelial cells [12]. In contrast, $\beta$-catenin inhibits migration of human epithelial cells in vitro, which may impair wound closure in vivo [13]. Hyperplastic wounds in man exhibit a prolonged phase of elevated $\beta$-catenin protein levels and concurrent tcf-dependent transcriptional activation of target genes involved in fibroproliferative processes, such as alpha smooth muscle actin ( $\alpha$-SMA), fibronectin (FN) and collagen type III (COLIII) [5]. A transgenic mouse model, in which stabilized $\beta$-catenin is expressed in mesenchymal cells, develops aggressive fibromatosis (desmoid tumors) and hyperplastic cutaneous wounds [11].

PECAM1 (CD31) is a $130-\mathrm{kDa}$ transmembrane glycoprotein member of the immunoglobulin superfamily that is constitutively expressed on platelets, specific cells of the immune system, as well as on endothelial cells, particularly at intercellular junctions [14]. Its ectodomain mediates adhesion [15] while its cytoplasmic portion serves as a scaffold for cytoskeletal proteins [16] and for signaling [17]. PECAM1 has been implicated in a number of important biological processes including modulation of adhesion [18], cell migration [19], inflammatory cell infiltration [20,21], phagocytosis by macrophages [22], endothelial permeability [23] and angiogenesis [24,25].

PECAM1 binds tyrosine-phosphorylated $\beta$-catenin having left AJs and become localized to the cytosol [16]. Precisely, PECAM1 functions as a reservoir for tyrosine-phosphorylated $\beta$-catenin, maintaining localization at the plasma membrane. This dynamic interaction is involved in the proliferation phase of angiogenesis [16]. Biswas et al. [7] identified PECAM1 as a modulator of microvascular endothelial cell proliferation via its participation in the Wnt signaling pathway, thereby stabilizing and promoting the accumulation of transcriptionally active $\beta$-catenin.

In the present study we hypothesized that the temporal expression pattern of these two genes with potential roles in angiogenesis and cell proliferation would differ between body wounds which heal normally and limb wounds which are predisposed to the formation of EGT in horses. The specific objectives of this study were to characterize the full-length equine CTNNB1 and PECAM1 CDNAs, and to study the spatio-temporal expression profile of their mRNAs and proteins during the repair of body and limb wounds. The ultimate objective of our research program is to contribute to a better understanding of the dermal repair process, and permit the development of novel diagnostic and therapeutic strategies to resolve wound healing complications in the horse and which could ultimately be extrapolated to man. 


\section{Results \\ Cloning and characterization of equine CDNA for CTNNBI and PECAMI}

The cDNA fragments used for the virtual Northern analyses came from sequences previously obtained from a gene expression profiling experiment using SSH screening aimed at identifying mRNAs that were increased or induced during the proliferative phase of wound repair in the horse [4].

Screening of the size-selected library from equine thoracic wound margin biopsies collected $7 \mathrm{~d}$ post-operatively for CTNNB1 cDNA resulted in the cloning of a truncated cDNA fragment. Thus, a PCR reaction was performed to characterize 5' upstream sequences of the ORF. The equine CTNNB1 cDNA characterized consisted of 2382 bp [GenBank:DQ267491] that included a partial 5'untranslated region (UTR) of $9 \mathrm{bp}$, an ORF of $2346 \mathrm{bp}$ encoding a 781-amino acid protein with a theoretical molecular weight of $85.5-\mathrm{kDa}$, an isoelectric point of 5.5 , and a partial 3'-UTR of $27 \mathrm{bp}$. Amino acid homology search in GenBank by PsiBlast revealed orthologous proteins with an overall identity level of $100 \%$ for porcine [GenBank:NM_214367], and 99\% to human [GenBank:NM 001904] and canine [GenBank:XM 856013] CTNNB1 proteins. The analysis against a protein conserved domains database (PROSITE) showed the presence of 9 Armadillo/plakoglobin ARM repeat profiles ( $\mathrm{R}^{151}$ $\mathrm{S}^{191}, \mathrm{Q}^{193}-\mathrm{G}^{236}, \mathrm{G}^{235}-\mathrm{G}^{277}, \mathrm{G}^{277}-\mathrm{G}^{319}, \mathrm{G}^{319}-\mathrm{G}^{362}, \mathrm{G}^{400}$ $\left.\mathrm{G}^{442}, \mathrm{G}^{442}-\mathrm{A}^{484}, \mathrm{Y}^{489}-\mathrm{A}^{532}, \mathrm{~N}^{594}-\mathrm{A}^{636}\right)$.

The virtual Northern analyses allowed determination of the approximate molecular weight of the full-length PECAM1 cDNA, which corresponded to $3.1-3.7 \mathrm{~kb}$. The SSH cDNA fragment was thus used as probe to screen, by hybridization, the appropriate size-selected cDNA library generated from equine thoracic wound margin biopsies collected $7 \mathrm{~d}$ post-operatively. The full-length equine PECAM1 cDNA was cloned and consisted of 3381 bp [GenBank:DQ310372] that included a 5'-untranslated region (UTR) of $156 \mathrm{bp}$, an ORF of $2217 \mathrm{bp}$ encoding a 738-amino acid protein with a theoretical molecular weight of $82.3-\mathrm{kDa}$, an isoelectric point of 8.2 , and a 3'UTR of 1008 bp containing one polyadenylation signal. Amino acid homology search in GenBank by PsiBlast revealed orthologous proteins with an overall identity level of 76\% to canine [GenBank:XM 848326], 75\% to porcine [GenBank:NM 213907], and 72\% to human [GenBank:NM_000442] and bovine [GenBank:NM 174571] proteins. The equine sequence determined herein contains the 16 exons present in the predominant form of full-length human PECAM1 [26]. While our study does not exclude the possibility of PECAM1 isoforms in the horse, in normal skin and wound edge biopsies we detected only the full-length isoform for PECAM1.

\section{Temporal expression of CTNNBI and PECAMI mRNAs in body and limb wounds}

Semi-quantitative RT-PCR showed an induction of CTNNB1 mRNA expression in response to wounding though up-regulation was less acute than for PECAM1. The repeated measures linear model revealed a non-significant effect of site, across time $(P=0.49)$ when used to analyze the temporal expression of CTNNB1 mRNA during wound repair in the horse, though constitutive expression of CTNNB1 in unwounded skin at time 0 was significantly greater in the limb than in the thorax $(\mathrm{P}=$ 0.0014; Fig 1). Statistical analysis of the results obtained for CTNNB1 mRNA expression revealed a significant effect of time across groups $(P=0.0002)$. Expression was induced in thoracic skin in response to wounding, with significantly elevated levels attained from one week on. The level of expression of CTNNB1 mRNA was significantly greater in thoracic than limb wounds from three

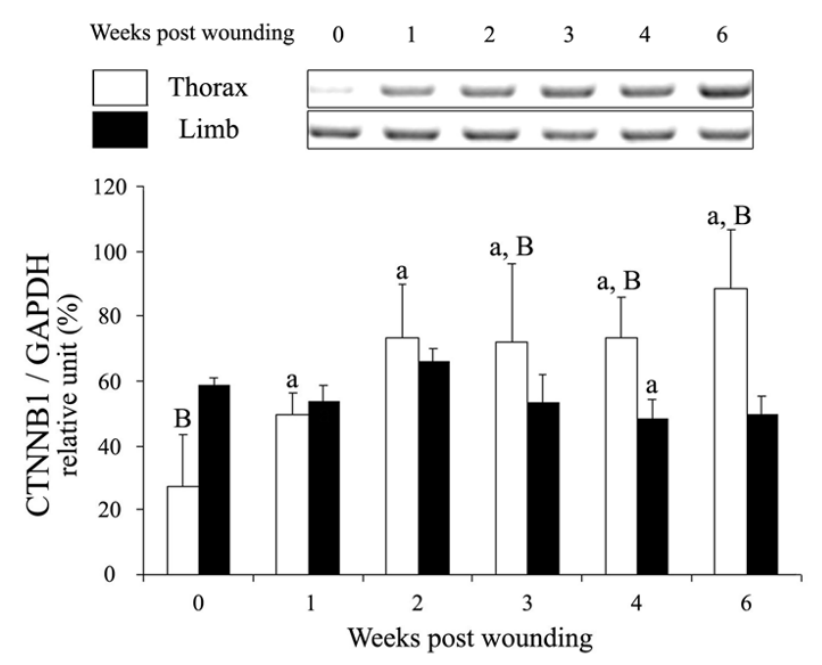

\section{Figure I}

Regulation of equine CTNNB I mRNA by wounding of thorax and limb skin. Total RNA was extracted from wound margin biopsies isolated I, 2, 3, 4 and 6 weeks post-wounding, then used in mRNA expression analyses by semi-quantitative RTPCR as described in Methodology. Bar graphs represent the average of measures, performed in triplicate, on the mRNA of the four horses included in the study. Top: Regulation of CTNNBI mRNA (AF 752 bp) in wound biopsies from the thorax and the limb. Bottom: Relative changes in CTNNBI mRNA in biopsies of thorax and limb wounds. The intensity of CTNNBI signals was normalized with the control gene $G A P D H$. Different letters denote samples that differed significantly $(P<0.05)$ from time 0 of the same site $(a)$; between anatomic sites at the same time $(B)$. Data are presented as means \pm SEM. 
weeks on; after six weeks of repair, RT-PCR showed a persistent induction of CTTNB1 in thoracic wounds.

The repeated measures linear model revealed a non-significant effect of site, across time $(P=0.93)$, when used to analyze the temporal expression of PECAM1 mRNA during wound repair in the horse, though constitutive expression of PECAM1 in unwounded skin was significantly greater in the limb than in the thorax $(P<0.03$; Fig 2$)$. Thereafter the effect of site varied from one time to another. Semi-quantitative RT-PCR showed an induction of mRNA expression in response to wounding, with a significantly higher level reached in thoracic than in limb wounds after only one week of repair $(\mathrm{P}=0.0174)$. PECAM1 mRNA expression did not return to baseline levels by the end of the 6-week study at either location. Indeed, the effect of time, across sites, was significant $(\mathrm{P}<$ 0.0001).
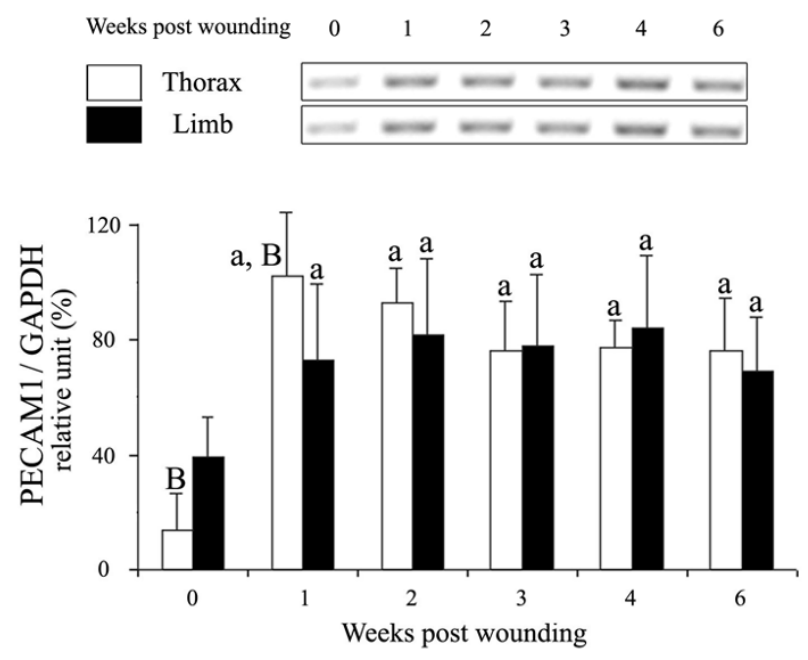

\section{Figure 2}

Regulation of equine PECAMI mRNA by wounding of thorax and limb skin. Total RNA was extracted from wound margin biopsies isolated I, 2, 3, 4 and 6 weeks post-wounding, then used in mRNA expression analyses by semi-quantitative RTPCR as described in Methodology. Bar graphs represent the average of measures, performed in triplicate, on the mRNA of the four horses included in the study. Top: Regulation of PECAMI mRNA [amplified fragment (AF) 548 bP] in wound biopsies from the thorax and the limb. Bottom: Relative changes in PECAMI mRNA in biopsies of thorax and limb wounds. The intensity of PECAMI signals was normalized with the control gene GAPDH. Different letters denote samples that differed significantly $(P<0.05)$ from time 0 of the same site (a); between anatomic sites at the same time (B). Data are presented as means \pm SEM.

\section{Protein localization in healing body and limb wounds}

Immunoblotting showed a specific band of the expected molecular weight in equine skin protein extract for $\beta$-catenin determining that the commercial mouse monoclonal antibody raised against amino acids 680-781 mapping at the $\mathrm{C}$-terminus of $\beta$-catenin of human origin (sc-7963; Santa Cruz Biotechnology) was specific for equine tissues (data not shown). Cellular localization of $\beta$-catenin in normal skin and wound tissues was determined by immunohistochemistry. In normal unwounded skin, the epidermis showed nuclear reactivity, which was also present in the sheaths of the hair follicles and some sebaceous glands (Fig 3a). No immunoreactive signal was noted in the extracellular matrix (ECM) or the fibroblasts populating the dermis, but endothelial cells were positively stained on their luminal side (Fig 3b). No qualitative or quantitative differences in staining were detected between thoracic and limb skin samples, nor later on between thoracic and limb wound samples. While epithelialization was incomplete two weeks following wounding, the intact epidermis adjacent to the wound continued to show nuclear reactivity but also new membrane reactivity at the wound edge (Fig 3c). The dermis contiguous to the wound showed the same pattern as pre-operatively while the granulation tissue filling the wound bed showed nuclear and cytoplasmic staining of both the fibroblasts and the microvascular endothelial cells. In the fourth week of repair the epidermis and the dermis showed the same staining pattern as described for the second week samples. The granulation tissue fibroblasts were strongly stained in a nuclear fashion while the endothelial cells were also labelled with the anti- $\beta$-catenin antibody. Six weeks following wounding, immunostaining for $\beta$-catenin protein had started to wane. The epidermis, which covered the wound bed in most cases, showed the nuclear staining pattern observed pre-operatively in intact skin. The granulation tissue, which had become less cellular, was weakly stained compared to that of four week biopsies and exhibited a staining pattern more nuclear than cytoplasmic. In three month and six month old EGT, fibroblasts as well as endothelial cells appeared strongly stained in a nuclear/cytoplasmic fashion (Fig 3d).

The commercially available PECAM1 antibody (sc-1506; Santa Cruz Biotechnology) stained very specifically endothelial cell membranes, as expected. The PECAM1 antibody stained the luminal membrane of endothelial cells lining dermal blood vessels in normal, unwounded skin (Fig 4a) and in wound biopsies. Consequently, the staining pattern paralleled that of angiogenesis following wounding. At weeks 1 and 4 the presence of more blood vessels within the granulation tissue filling the wound bed translated into more PECAM1 immunostaining, particularly in limb wounds (Figs 4c and 4d). In 3 month old EGT, there were large and strongly PECAM1-positive ves- 

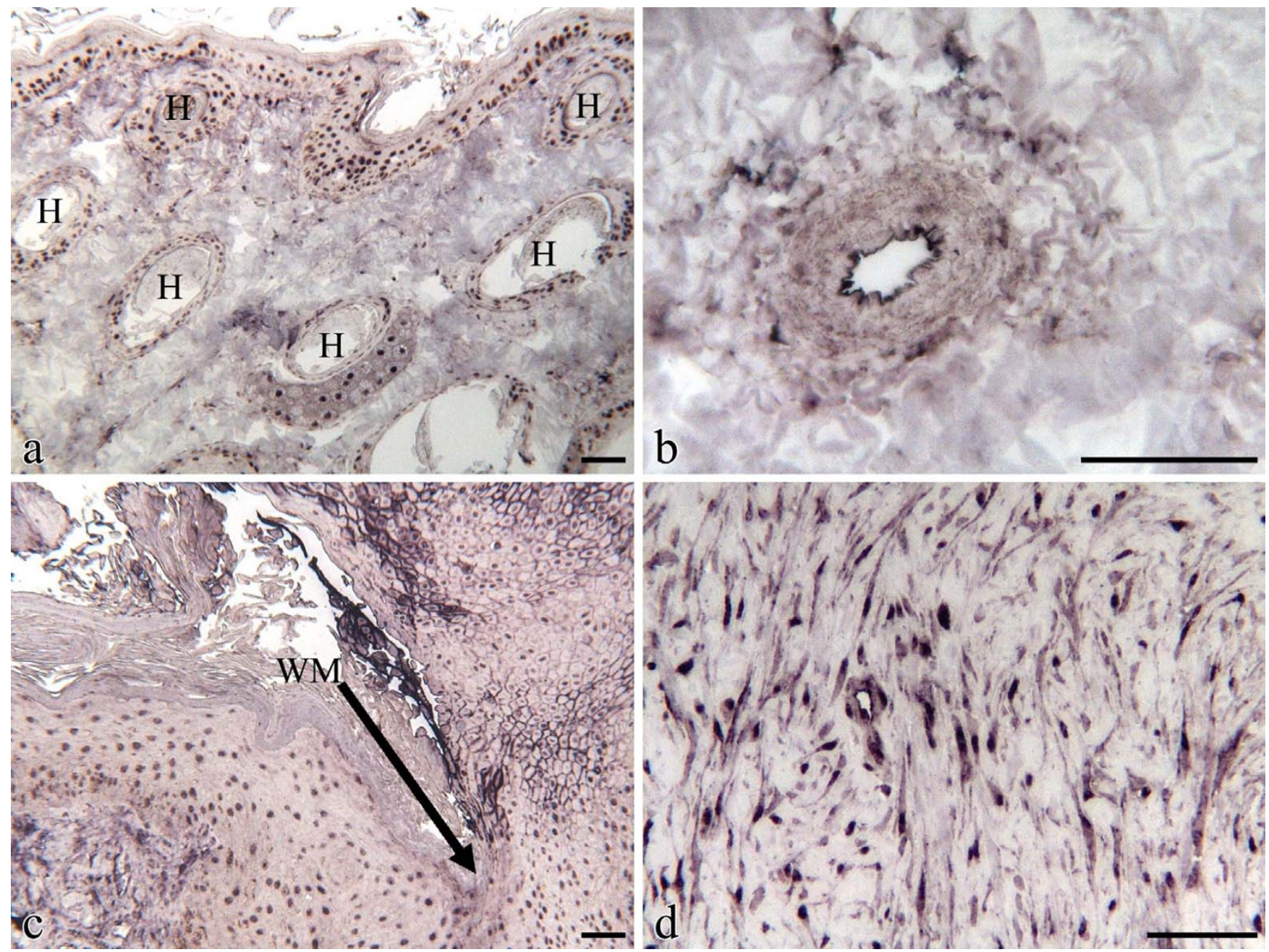

Figure 3

Immunohistochemical localization of $\beta$-catenin in the epidermal compartment of equine skin or wounds. Immunohistochemistry was performed on formalin-fixed, paraffin embedded tissues incubated with anti- $\beta$-catenin antibody as described in Methodology. Staining was absent when the primary antibody was omitted or substituted with normal serum (data not shown). The scale bar is equal to $0.1 \mathrm{~mm}$. a) Unwounded limb skin. $\mathrm{H}=$ hair follicle. b) Unwounded limb skin. Endothelial cells stained with $\beta$-catenin antibody. c) Wound margin biopsy taken from 2 week old limb wound. WM = wound margin. d) 3 month old exuberant granulation tissue.

sels while in 6 month old EGT the vessels were smaller and more organized such that the PECAM1 staining was slightly weaker (Fig 4b).

\section{Discussion}

The purpose of this study was to determine the temporal expression of CTNNB1/ $\beta$-catenin and of PECAM 1 during the repair of body and limb wounds in horses in an effort to define some of the molecular mechanisms leading to undue scarring. At the time of the study, the cDNAs were not characterized for the horse therefore both were cloned and sequenced. Hybridization of the size-selected libraries revealed the clones containing the full-length sequence of PECAM1 but only a truncated fragment of CTNNB1.
Fortunately, the latter allowed the design of a homologous oligonucleotide that was used, along with a heterologous one, to amplify the full-length equine CTNNB1 cDNA sequence.

Results show equine CTNNB1 to be a highly conserved gene and to contain all 16 exons reported in humans. The excellent identity of the sequences for CTNNB1 in mammals (close to $100 \%$ ) validates the quality of the equine sequence we obtained despite the required amplification by PCR. A high rate of degradation may have contributed to our inefficiency in obtaining the correct hybridization size for the full-length CTNNB1 gene in horse; indeed, in man there exists in the 3'-UTR one copy of AU-rich ele- 

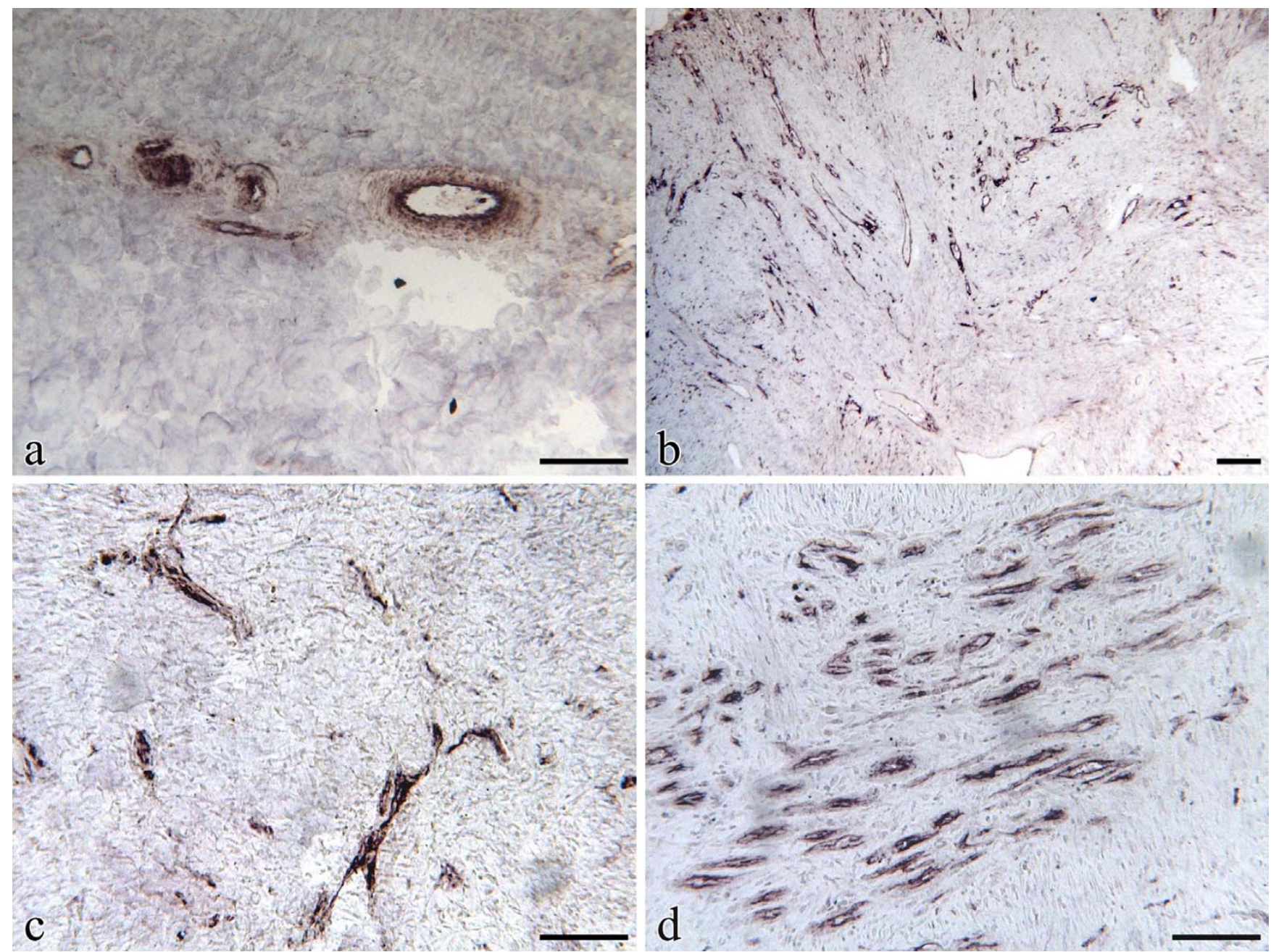

Figure 4

Immunohistochemical localization of PECAMI in the dermal compartment of equine skin or wounds tissues. Immunohistochemistry was performed on formalin-fixed, paraffin embedded tissues incubated with anti-PECAMI antibody as described in Methodology. The blood vessel endothelial cells are stained. Staining was absent when the primary antibody was omitted or substituted with normal rabbit serum (data not shown). The scale bar is equal to $0.2 \mathrm{~mm}$. a) Unwounded thoracic skin. b) 6 month old exuberant granulation tissue. c) Wound margin biopsy (focusing on granulation tissue) taken from 4 week old healing thoracic wound. d) Wound margin biopsy (focusing on granulation tissue) taken from 4 week old healing limb wound.

ment (ATTTA), a motif known to contribute to short lived mRNAs.

CTNNB1, first cloned by McCrea et al. [27] in Xenopus laevis, shows no similarity in sequence to the genes for the $\alpha$-catenins reported in other species while the $\beta$-catenin protein shares $70 \%$ amino acid identity with both plakoglobin, found in desmosomes, and the product of the Drosophila segment polarity gene "armadillo". Analysis of equine predicted $\beta$-catenin, against a protein conserved domains database (PROSITE), showed the presence of 9 Armadillo/plakoglobin repeat profiles, an approximately 40 amino acid long repeated sequence motif. Proteins that contain this type of domain combine structural roles and signaling functions, by generating and transducing signals affecting gene expression [28]. The calculated expected molecular weight $(85,5 \mathrm{kDa})$ concords with that previously reported for other species.

A preliminary mRNA gene expression profiling study identified a cDNA fragment that corresponded to PECAM1, suggesting its up-regulation in response to dermal wounding [4]. The equine sequence determined herein contained the 16 exons present in the full-length human PECAM1, the predominant isoform detected in human tissue and endothelial cells [26]. This contrasts with the main isoform found in murine endothelium which lacks exons 14 and 15 [29]. While it is possible that 
other isoforms also exist in horses, our data suggest that, at least in skin, the full-length form predominates.

Processes occurring during the proliferative phase of wound repair ensure restoration of the structural and functional characteristics of skin which depend on both the epithelial and the mesenchymal components of the wound. The severity of scarring of horse limb wounds is related to an excessive proliferative phase where angiogenesis and fibroplasia are exacerbated [30-33]. This may result from dysregulation of the molecular components governing the growth of mesenchymal cells. In the study reported herein we have focused on two molecules, CTNNB1 and PECAM1, for their proposed role in endothelial cell and fibroblast proliferation.

The temporal patterns we report for mRNA expression of CTNNB1 and PECAM1 resemble one another. Both genes were constitutively expressed in normal intact skin, but while dermal trauma induced the expression of both mRNAs, the response was more acute for PECAM1 whose levels were significantly increased over baseline one week following wounding compared to two weeks for CTNNB1. This significant up-regulation of mRNA was maintained for the duration of the study for PECAM1 at both anatomic locations and for CTNNB1 in thoracic wounds; conversely, expression of CTNNB1 in limb wounds was not significantly elevated following wounding. Finally, mRNA expression in thoracic wounds significantly surpassed that of limb wounds for PECAM1, one week post-wounding, and for CTNNB1, three, four and six weeks post-wounding.

While possible that the temporal pattern of mRNA expression might reflect the different levels at the various sampling sites, the wounds were very close together such that we think it unlikely that anatomic or metabolic differences (blood supply, muscle coverage, etc) are important. Previous studies using a similar model [30-33] have not reported an influence of the exact location on the body or the lower limb. Likewise a current study has shown no difference in the rate of closure between wounds located distally or more proximally on the lower limb (Monteiro et al, unpublished data).

The correspondence in the patterns of mRNA expression following wounding is consistent with the PECAM $1 / \beta$ catenin protein partnership proposed by Biswas et al. $[7,34,35]$. Indeed, the cytoplasmic portion of PECAM1 binds cytosolic $\beta$-catenin and this dynamic interaction is involved in angiogenesis [16]. More specifically, by enhancing the accumulation of stabilized $\beta$-catenin, PECAM1 modulates microvascular endothelial cell proliferation via transcriptional activation of growth promoting genes. Furthermore, a significant increase in PECAM1
mRNA levels preceded that of CTNNB1 following wounding in our study, consistent with the fact that upon cytokine stimulation endothelial cells initially induce PECAM1, followed by an increased expression of $\beta$-catenin [7].

While one might have anticipated higher levels of equine CTNNB1 mRNA in limb wounds predisposed to the development of EGT, a form of fibroproliferative disease, our opposite findings may reflect the mechanism of posttranscriptional regulation of $\beta$-catenin during wound repair, which controls how mRNA is translated into protein. Indeed, Cheon et al. documented that in the absence of any change in mRNA level, $\beta$-catenin protein, expressed primarily in dermal mesenchymal cells, was nonetheless transiently increased during the proliferative phase of normal wound healing in humans while exhibiting a sustained elevation in hyperplastic wounds [5]. Thus, a lack of correlation between mRNA and protein levels might underlie our unexpected findings; specifically, why CTNNB1 mRNA levels remained elevated when immunostaining for $\beta$-catenin waned, and why CTNNB1 mRNA levels in thoracic wounds surpassed those of limb wounds at weeks 3, 4 and 6 of healing.

In the horse, epithelial cells migrate slowly on limb wounds which are concurrently afflicted by over-abundant fibroblast proliferation; both are influences attributed to $\beta$-catenin protein $[10,13]$. Although immunohistochemical studies did not suggest quantitative differences in $\beta$-catenin expression between body and limb wounds, our investigation did reveal that while the protein remains transcriptionally active (nuclear stain) in dermal mesenchymal cells for the duration of the study, the intensity of the stain diminishes between the $4^{\text {th }}$ and $6^{\text {th }}$ weeks of healing. This pattern suggests that the signal would have disappeared entirely from normally healed wounds had the study been extended a few weeks. Conversely, strong immunostaining for $\beta$-catenin was detected in biopsies of 3 and 6 month old EGT, a condition characterized by exaggerated angiogenesis and fibroplasia and which resembles hyperplastic scarring in man in which a prolonged duration of $\beta$-catenin protein elevation has been reported [5]. Our findings may indicate that mesenchymal cells in EGT are behaving as though in a prolonged active proliferative phase of wound healing. In other words, the high levels of $\beta$-catenin would encourage proliferation and motility of the dermal cells, generating a larger dermal component to the wounds and hampering remodeling which requires reduced $\beta$-catenin levels [5].

While the design of our study cannot establish a causeand-effect relationship between the prolonged elevation of $\beta$-catenin and the development of equine EGT, transgenic mouse models expressing a stabilized form of $\beta$-cat- 
enin in mesenchymal cells develop hyperplastic cutaneous wounds [11]. Fibroblasts derived from these mice display increased proliferation, motility and invasiveness when grafted into nude mice. Moreover, primary cell cultures demonstrate Tcf-dependent transcriptional activation [11] consistent with the hypothesis that nuclear $\beta$-catenin transactivation of target genes is a primary component of fibrosis.

In contrast to the membrane staining of epithelial cells reported by Cheon et al [5], we identified nuclear $\beta$-catenin within epithelial cells of intact skin. Our finding is similar to that of Tsuji et al. [36] who report nuclear immunostaining for $\beta$-catenin from the upper spinous to the granular cells in normal, intact human epidermis. The presence of stabilized, transcriptionally active $\beta$-catenin no doubt reflects keratinocyte proliferation and differentiation in response to continued renewal of the epithelial component of equine skin $[37,38]$.

While PECAM1 is best known as a promoter of angiogenesis, its ability to facilitate neutrophil transendothelial migration $[20,21]$ and thus boost the acute inflammatory response [39] is particularly intriguing in view of the data obtained herein. Indeed, it is tempting to draw a parallel between the inefficient and prolonged inflammatory response to wounding in the horse limb [33] and the significantly inferior expression of PECAM1 mRNA in wounds at this site compared to those of the thorax, one week following injury. Conversely, while differences in expression between the two sites disappear from the second week on, one might have expected an increase in limb wounds where new blood vessels are particularly abundant within the granulation tissue [33], in relation to PECAM1's role in angiogenesis. Interestingly, the expression pattern of PECAM1 isoforms has been shown to change during tube formation in vitro, indicating specialized roles for specific isoforms of PECAM1 during angiogenesis [26]. While our data suggest that we have cloned the predominant isoform of equine PECAM1, it is possible that another isoform is responsible for modulating endothelial cell adhesive properties during angiogenesis in the horse. Finally, the PECAM1 mRNA expression pattern found in our study corroborates previous assertions concerning the sluggishness hindering the repair of equine wounds, particularly those located on the extremities $[1,30,33]$. To this effect, a recent study in mice showed that both mRNA and protein expression of PECAM1 were induced three days following dermal wounding but mRNA expression returned to baseline by day 12 [40]. In contrast, expression of equine PECAM1 mRNA was significantly up-regulated in both thoracic and limb wounds for the 6-week duration of the study.
Immunohistochemistry revealed that, as expected of an endothelial cell marker, PECAM1 is principally present in blood vessels. As such, our data reflect that previously reported by Lepault et al. [33] who documented, histologically, more pronounced angiogenesis in healing limb than body wounds of horses. The concomitant presence of PECAM 1 and $\beta$-catenin on endothelial cells of wound granulation tissue further supports the dynamic interaction between these two molecules, which may modulate the proliferation phase of angiogenesis $[7,16]$.

\section{Conclusion}

This study is the first to characterize equine cDNA for CTNNB1 and PECAM1 and to document that the genes are expressed over the different phases of wound repair in horses. Our findings suggest that $\beta$-catenin and PECAM1 might interact to modulate endothelial cell and fibroblast proliferation during wound repair in the horse.

Most previous studies investigating the roles of $\beta$-catenin and PECAM1 in wound healing have used in vitro techniques. Since wound repair is a complex process involving the interplay of several cell types, signaling pathways, extracellular matrix components and soluble factors, the role of various factors and their interactions may best be evaluated using an in vivo approach. Thus, while data interpretation can be challenging, the value of our study lies in the fact that the findings are more representative of what truly occurs in the patient.

In an effort to develop targeted therapies to prevent the formation of EGT leading to excessive scarring of equine limb wounds, future studies should quantitatively verify the temporal protein expression of $\beta$-catenin and PECAM 1 and attempt to elucidate how the two molecules interact. The clues gained from studying the equine model may eventually lead to new insights into how to prevent unwanted scar formation in humans.

\section{Methods \\ Cloning of equine CTNNBI and PECAMI}

Isolation of the full-length equine cDNAs was undertaken by screening size-selected cDNA libraries. The sizes of the full-length equine PECAM1 and CTNNB1 CDNA were estimated by virtual Northern blot analysis. Briefly, total RNA was isolated from a wound edge biopsy obtained 7 days following creation of a square $6.25 \mathrm{~cm}^{2}$ full-thickness wound on the lateral thoracic wall [4] and transformed into cDNA by the SMART cDNA synthesis method (BD Biosciences Clontech, Mississauga ON) as described [41]. The cDNA was separated by gel electrophoresis, transferred onto a nylon membrane and hybridized with an equine radioactive probe $(C T N N B 1=535$ bp: [GenBank:DN625863]; PECAM1 = 492 bp: [GenBank:DN625893]) generated from a previous gene 
expression profiling experiment [4]. On the basis of the hybridized size, a specific library was established via the pDrive plasmid cloning technique (Qiagen PCR cloning kit; Qiagen, Mississauga ON) and screened by radioactive hybridization as described [41]. Positive hybridizing bacterial colonies were grown, their plasmid contents were isolated (QIA-prep, Qiagen) and the size of the cloned cDNA was analyzed via gel electrophoresis analysis following EcoR1 digestion.

Since only a 3'-truncated cDNA fragment was obtained for CTNNB1 following library screening, a PCR reaction was performed to characterize 5 ' upstream sequences. Oligos were designed based on conserved regions of human [GenBank:NM 001904], swine [GenBank:NM 214367] and murine [GenBank:NM 007614] sequences. PCR reactions were performed using SMART cDNAs from a 7 day wound edge biopsy, Advantage 2 DNA polymerase (BD Biosciences Clontech) and PCR primers (sense: 5'-GCGTGGACAATGGCTACYCAAGC-3'; anti-sense: 5'-CCAGGCCAGCTGATTACTGTCAC-3'). The PCR product was cloned in the pDrive plasmid and produced as described above.

The cDNAs were sequenced via the dideoxy sequencing method (Big Dye Terminator 3.0; ABI Prism, Applied BioSystem, Branchburg NJ) and analyzed on an ABI Prism 310 sequencer (Applied BioSystem). Nucleic acid sequences were analyzed by BLAST and protein sequences deduced from cDNAs were analyzed by PSI- and PHIBLAST [42] against GenBank data banks.

\section{Equine tissues and RNA extraction}

Thoracic and limb normal skin as well as wound edge biopsies were taken at specific times during the repair process from four normal, 2-to-3 year old Standardbred mares, as described [33]. Briefly, five square $6.25 \mathrm{~cm}^{2}$ areas were excised on the dorso-lateral aspect of one randomly assigned metacarpus beginning just above the fetlock, and on the lateral thoracic wall, $1.5 \mathrm{~cm}$ apart in a staggered vertical column, then left to heal by second intention. Excised skin from the lowermost wound was kept as a time 0 sample. One wound per site (thorax; limb) was sampled at the following times in each horse: $1,2,3,4$, and 6 weeks. To avoid repeated trauma, each wound, beginning with the most distal one, was designated for a single biopsy. Full-thickness specimens were taken with an $8 \mathrm{~mm}$ diameter biopsy punch to include a 3-to-4 mm strip of peripheral skin, the migrating epithelium and a 3-to-4 $\mathrm{mm}$ strip of granulation tissue from the wound center, when present. Biopsy samples were divided in half; one half was formalin-fixed and paraffin-embedded (FFPE) for immunohistochemical studies while the other was snap-frozen in liquid nitrogen and stored at $80^{\circ} \mathrm{C}$ until further processing. Total RNA from all samples was extracted and analyzed as previously described [43]. Samples of 3 and 6 month old EGT were obtained from two clinical cases presented to the Centre Hospitalier Universitaire Vétérinaire of the Université de Montréal and FFPE for immunohistochemistry. These experiments were approved by the Animal Ethics Committee of the Faculté de Médecine Vétérinaire of the Université de Montréal and were sanctioned by the Canadian Council on Animal Care.

\section{Semi-quantitative RT-PCR analyses of temporal expression of mRNA}

Total RNA was first transformed into cDNA. One $\mu \mathrm{g}$ of total RNA from samples of healing thoracic wounds ( $\mathrm{n}=$ 4 mares) was pooled for each biopsy time; the same was done for limb wound samples. From each of these pools, RNA was reverse-transcribed with an oligo-dT30 primer and PowerScript (BD Biosciences Clontech) to generate the first strand CDNA using the SMART PCR CDNA synthesis kit (User manual: PT3041-1; BD Biosciences Clontech) [44]. Second cDNA strands were produced and PCRamplified using Advantage 2 DNA polymerase (BD Biosciences Clontech). To perform semi-quantitative RTPCR, SMART CDNA pools were used in a $25 \mu \mathrm{l}$ PCR reaction with the Advantage 2 DNA polymerase kit (BD Biosciences Clontech). Gene-specific PCR primers were designed in the open reading frame (ORF) of the equine CDNA sequence for: CTNNB1 (sense: 5'-GGACCACAAGCAGAGTATTGAAGG-3'; anti-sense: 5'-AATTCGGTTGTGAACATCCCGAGC-3'; [GenBank:DQ267491]), PECAM1 (sense: 5'-GGGACATATACCTGCACCGCA-3'; anti-sense: 5'-TTACTCGCCTGCGACTCATGC-3'; [GenBank:DQ310372]) and glyceraldehyde-3-phosphate dehydrogenase (GAPDH; sense: 5'-CAAGTTCCATGGCACAGTCACGG-3'; anti-sense: 5'-AAAGTGGTCGTTGAGGGCAATGC-3'; [GenBank:AF157626]) [4]. For all samples, PCR was performed in triplicate by Mastercycler ${ }^{\circledast}$ ep. The number of cycles used was optimized for each gene to fall within the linear range of PCR amplification: GAPDH $=18$ cycles; $C T N N B 1=23$ cycles; PECAM $1=22$ cycles. The PCR reactions $(20 \mu \mathrm{l} /$ reaction $)$ were resolved on a 2\% TAE-agarose gel ( $40 \mathrm{mM}$ Tris acetate; $\mathrm{pH} 8 ; 1 \mathrm{mM}$ EDTA) with ethidium bromide $(0.5 \mu \mathrm{g} / \mathrm{ml})$; PCR products were visualized by UV and the images were digitized. The digitized signals for each gene were analyzed by densitometry using the NIH Image program [45].

\section{Immunoblot analyses}

Specimens of equine skin and platelets were homogenized in M-PER buffer (Pierce, Rockford, IL) that was supplemented with a mix of protease inhibitors (Complete; Roche Applied Science, Laval, QC) as recommended by the manufacturer. Samples were homogenized at 7,000 rpm with a polytron PT1300D (Kinematica AG, LittauLucerne, Switzerland). The protein extracts were centri- 
fuged at $10,000 \times \mathrm{g}$ for $5 \mathrm{~min}$ at $4^{\circ} \mathrm{C}$, and the recovered supernatant (whole cell extract) was stored at $-80^{\circ} \mathrm{C}$ until electrophoretic analyses were performed. Protein concentration was determined by the Bradford method [46] (BioRad Protein assay, Bio-Rad Laboratories Inc., Hercules, CA). Protein extracts ( $100 \mu \mathrm{g}$ proteins/sample) were heattreated $\left(5 \mathrm{~min}, 100^{\circ} \mathrm{C}\right)$ and size-fractionated via a onedimensional SDS-PAGE, then electrophoretically transferred onto polyvinylidene difluoride membranes (PVDF; Hybond-P, Amersham Pharmacia Biotech). Immunoblots were performed as described [47]. Membranes were incubated either with the mouse anti-human $\beta$-catenin monoclonal antibody (dilution 1:1,000; sc-7963; Santa Cruz Biotechnology, Inc.) or with the goat anti-mouse PECAM1 polyclonal antibody (dilution 1:200; sc-1506; Santa Cruz Biotechnology, Inc. Santa Cruz, CA). As secondary antibodies a sheep anti-mouse IgG-HRP (dilution 1:10,000; NA931; Amersham Pharmacia Biotech) and a donkey anti-goat IgG-HRP (dilution 1:5,000; sc-2020; Santa Cruz Biotechnology, Inc.) were used. Detection of immunoreactive proteins was performed by the enhanced chemiluminescence system (ECL Plus, Amersham Pharmacia Biotech) following the manufacturer's protocol, and exposed to Hyperfilm (Amersham Pharmacia Biotech). Autoradiographic images were digitized using a ScanMaker 9800XL flatbed scanner (Microtek lab, Inc., Redondo Beach CA).

\section{Immunohistochemical localization of $\beta$-catenin and PECAMI}

PBS-buffered formalin-fixed tissues from both locations (thorax and limb) in all four horses were prepared as described [47]. Paraffin-embedded tissues were cut to 3 $\mu \mathrm{m}$ thickness, mounted on SuperfrostPlus slides (Fisher Scientific, Pittsburgh PA), deparaffinized and then rehydrated. Antigenicity lost during the fixation process was retrieved by pressure cooker heat treatment for $15 \mathrm{~min}$ [47]. Non-specific binding sites were saturated by $30 \mathrm{~min}$ incubation in blocking buffer: TBS ( 100 mM Tris; $\mathrm{pH} 7.5$; $150 \mathrm{mM} \mathrm{NaCl}$ ), $1 \%$ bovine serum albumin and $1 \%$ fatfree skim milk. For the antibody raised in goat, the fat-free skim milk was omitted; the saturation step was substituted by 30 min incubation in TBS-tween (100 mM Tris; $\mathrm{pH} 7.5$; Tween $0.2 \%$ ) Tissue sections were incubated overnight at $4{ }^{\circ} \mathrm{C}$ with the primary antibodies $(\beta$-catenin $1: 25$; PECAM1 1:50) diluted in blocking buffer. Negative control tissue sections were incubated similarly. After three 10 min washes in TBS, complexes were detected by incubation for $2 \mathrm{~h}$ at room temperature with an anti-goat/mouse IgG alkaline phosphatase conjugated (Sigma-Aldrich) diluted to 1:100 in blocking buffer. Tissue sections were washed twice in TBS and once in TBS- $\mathrm{MgCl}_{2}(100 \mathrm{mM}$ Tris $\mathrm{pH} 9.5,50 \mathrm{mM} \mathrm{MgCl}_{2}$ ) and incubated with the NBT/BCIP alkaline phosphatase substrate (Roche Applied Science). Sections were mounted in Vectamount ${ }^{\circledR}$ Permanent
Mounting Medium (Vector Laboratories, Burlingame CA). Photographs were taken under bright field illumination using a Nikon Eclipse E400 microscope equipped with a digital camera (Nikon Coolpix 4500). Digital images were processed and assembled by Photoshop software (Adobe Systems Inc., San Jose CA).

\section{Statistical analysis}

Gene-specific signals (CTNNB1; PECAM1) were normalized with corresponding GAPDH signals for each sample. A repeated-measures (RM) linear model, with site (thorax vs limb) and biopsy time as within-subject factors, was used to determine the effects of site and time on gene expression. When the RM linear model indicated significant differences $(\mathrm{P}<0.05)$, a priori contrasts were used to compare pre-selected individual means. All analyses were carried out with a P value $<0.05$, using SAS v. 9.1. (Cary, N.C.).

\section{Authors' contributions}

VM, ZI and JLL were responsible for generating the majority of the data, including analysis of the wound healing experiments: ZI was responsible for the cloning; VM and JLL contributed to the cloning and carried out the immunoblotting and the immunohistochemistry; VM helped to draft the manuscript.

JGL and CLT were the senior investigators who conceived the study and participated in its design and coordination; CLT drafted the manuscript and JGL helped in the drafting.

All authors read and approved the final manuscript.

\section{Acknowledgements}

This work was funded by a discovery grant (CLT) from the Natural Sciences and Engineering Research Council (NSERC) of Canada. VM was the recipient of a PhD scholarship from the Italian Education, University and Scientific Research Ministry. Neither funding body played a role in study design; in the collection, analysis, and interpretation of data; in the writing of the manuscript; nor in the decision to submit the manuscript for publication.

The authors thank Guy Beauchamp for help with statistical analysis.

\section{References}

I. Jacobs KA, Leach DH, Fretz PB, Townsend HGG: Comparative aspects of the healing of excisional wounds on the leg and body of horses. Vet Surg 1984, I 3:83-90.

2. Knottenbelt DC: Equine wound management: are there significant differences in healing at different sites on the body? Vet Dermatol 1997, 8:273-290.

3. Perkins NR, Reid SW, Morris RS: Profiling the New Zealand Thoroughbred racing industry. 2. Conditions interfering with training and racing. $N Z$ Vet $J$ 2005, 53(I):69-76.

4. Lefebvre-Lavoie J, Lussier JG, Theoret CL: Profiling of differentially expressed genes in wound margin biopsies of horses, using suppression subtractive hybridization. Physiol Genomics 2005, 22:157-70. 
5. Cheon S, Poon R, Yu C, Khoury M, Shenker R, Fish J, Alman BA: Prolonged beta-catenin stabilization and tcf-dependent transcriptional activation in hyperplastic cutaneous wounds. Lab Invest 2005, 85(3):4I6-425.

6. Bowley $E, O^{\prime}$ Gorman DB, Gan BS: Beta-catenin signaling in fibroproliferative disease. J Surg Res 2007, I 38(I): I 4I-I50.

7. Biswas P, Canosa S, Schoenfeld J, Schoenfeld D, Tucker A, Madri JA PECAM-I promotes beta-catenin accumulation and stimulates endothelial cell proliferation. Biochem Biophys Res Commun 2003, 303(I):212-2I8.

8. Nelson WJ, Nusse R: Convergence of Wnt, beta-catenin, and cadherin pathways. Science 2004, 303(5663): |483-|487.

9. Behrens J, von Kries JP, Kuhl M, Bruhn L, Wedlich D, GrosschedI R, Birchmeier W: Functional interaction of beta-catenin with the transcription factor LEF-I. Nature 1996, 382(6592):638-642.

10. Soler C, Grangeasse C, Baggetto LG, Damour O: Dermal fibroblast proliferation is improved by beta-catenin overexpression and inhibited by E-cadherin expression. FEBS Lett 1999, 442(2-3): $178-182$

II. Cheon SS, Cheah AY, Turley S, Nadesan P, Poon R, Clevers H, Alman BA: beta-Catenin stabilization dysregulates mesenchymal cell proliferation, motility, and invasiveness and causes aggressive fibromatosis and hyperplastic cutaneous wounds. Proc Natl Acad Sci USA 2002, 99(I 0):6973-6978.

12. Venkiteswaran K, Xiao K, Summers S, Calkins CC, Vincent PA, Pumiglia K, Kowalczyk AP: Regulation of endothelial barrier function and growth by VE-cadherin, plakoglobin, and betacatenin. Am J Physiol Cell Physiol 2002, 283(3):C8I I-C82I.

13. Stojadinovic O, Brem H, Vouthounis C, Lee B, Fallon J, Stallcup M, Merchant A, Galiano RD, Tomic-Canic M: Molecular pathogenesis of chronic wounds: the role of beta-catenin and c-myc in the inhibition of epithelialization and wound healing. Am J Patho 2005, I 67(I):59-69.

14. Newman PJ: Switched at birth: a new family for PECAM-I. Clin Invest 1999, I03(I):5-9.

15. Albelda SM, Muller WA, Buck CA, Newman PJ: Molecular and cellular properties of PECAM-I (endoCAM/CD3 I): a novel vascular cell-cell adhesion molecule. J Cell Biol 199I, I | 4(5): 1059-1068.

16. Ilan N, Mahooti S, Rimm DL, Madri JA: PECAM-I (CD3I) functions as a reservoir for and a modulator of tyrosine-phosphorylated beta-catenin. J Cell Sci I999, I I 2( I 8):3005-30 |4.

17. Ilan N, Mohsenin A, Cheung L, Madri JA: PECAM-I shedding during apoptosis generates a membrane-anchored truncated molecule with unique signaling characteristics. FASEB / 200I, I 5(2):362-372.

18. Berman ME, Xie Y, Muller WA: Roles of platelet/endothelial cell adhesion molecule-I (PECAM-I, CD3 I) in natural killer cel transendothelial migration and beta 2 integrin activation. J Immunol 1996, I56(4): I5I5-I524.

19. Cao G, O'Brien CD, Zhou Z, Sanders SM, Greenbaum JN, Makrigiannakis A, DeLisser HM: Involvement of human PECAM-I in angiogenesis and in vitro endothelial cell migration. Am J Physiol Cell Physiol 2002, 282(5):CI I8I-CI 90.

20. Nakada MT, Amin K, Christofidou-Solomidou M, O'Brien CD, Sun J, Gurubhagavatula I, Heavner GA, Taylor AH, Paddock C, Sun $\mathrm{QH}$ Zehnder JL, Newman PJ, Albelda SM, DeLisser HM: Antibodies against the first Ig-like domain of human platelet endothelial cell adhesion molecule-I (PECAM-I) that inhibit PECAM-I dependent homophilic adhesion block in vivo neutrophil recruitment. J Immunol 2000, I 64( I):452-462.

21. Thompson RD, Noble KE, Larbi KY, Dewar A, Duncan GS, Mak TW, Nourshargh S: Platelet-endothelial cell adhesion molecule-I (PECAM-I)-deficient mice demonstrate a transient and cytokine-specific role for PECAM-I in leukocyte migration through the perivascular basement membrane. Blood 2001 97(6): $1854-1860$.

22. Brown S, Heinisch I, Ross E, Shaw K, Buckley CD, Savill J: Apoptosis disables CD3 I-mediated cell detachment from phagocytes promoting binding and engulfment. Nature 2002 4l 8(6894):200-203

23. Lampugnani MG, Resnati M, Raiteri M, Pigott R, Pisacane A, Houen G, Ruco LP, Dejana E: A novel endothelial-specific membrane protein is a marker of cell-cell contacts. J Cell Biol 1992, | | 8(6): | 5||$-\mid 522$.
24. DeLisser HM, Christofidou-Solomidou M, Strieter RM, Burdick MD, Robinson CS, Wexler RS, Kerr JS, Garlanda C, Merwin JR, Madri JA, Albelda SM: Involvement of endothelial PECAM-I/CD3 I in angiogenesis. Am J Pathol I 997, I 5 I (3):67|-677.

25. Williams JL, Weichert A, Zakrzewicz A, Da Silva-Azevedo L, Pries AR, Baum $O$, Egginton $S$ : Differential gene and protein expression in abluminal sprouting and intraluminal splitting forms of angiogenesis. Clin Sci (Lond) 2006, I I 0(5):587-595.

26. Wang $Y$, Su X, Sorenson CM, Sheibani N: Modulation of PECAMI expression and alternative splicing during differentiation and activation of hematopoietic cells. J Cell Biochem 2003, 88(5): $1012-1024$

27. McCrea PD, Turck CW, Gumbiner B: A homolog of the armadillo protein in Drosophila (plakoglobin) associated with E-cadherin. Science |99|, 254(5036):|359-|36|.

28. Peifer $M$, Berg $S$, Reynolds $A B$ : A repeating amino acid motif shared by proteins with diverse cellular roles. Cell 1994, 76(5):789-79|

29. Sheibani N, Sorenson CM, Frazier WA: Tissue specific expression of alternatively spliced murine PECAM-I isoforms. Dev Dyn 1999, 2 | 4(I):44-54.

30. Wilmink JM, van Weeren PR, Stolk PW, Van Mil FN, Barneveld A: Differences in second-intention wound healing between horses and ponies: histological aspects. Equine Vet J 1999 , 3 I (I):6I-67.

3I. Theoret CL, Barber SM, Moyana TN, Gordon JR: Expression of transforming growth factor beta(I), beta(3), and basic fibroblast growth factor in full-thickness skin wounds of equine limbs and thorax. Vet Surg 200I, 30(3):269-277.

32. Schwartz AJ, Wilson DA, Keegan KG, Ganjam VK, Sun Y, Weber KT, Zhang J: Factors regulating collagen synthesis and degradation during second-intention healing of wounds in the thoracic region and the distal aspect of the forelimb of horses. Am J Vet Res 2002, 63( I I): I 564-I570.

33. Lepault E, Céleste C, Doré M, Martineau D, Theoret CL: Comparative study on microvascular occlusion and apoptosis in body and limb wounds in the horse. Wound Repair Regen 2005, I 3:520-529.

34. Biswas P, Zhang J, Schoenfeld JD, Schoenfeld D, Gratzinger D, Canosa $S$, Madri JA: Identification of the regions of PECAM-I involved in beta- and gamma-catenin associations. Biochem Biophys Res Commun 2005, 329(4): I 225-I233.

35. Biswas P, Canosa S, Schoenfeld D, Schoenfeld J, Li P, Cheas LC, Zhang J, Cordova A, Sumpio B, Madri JA: PECAM-I affects GSK-3betamediated beta-catenin phosphorylation and degradation. Am J Pathol 2006, I69(I):314-324.

36. Tsuji $H$, Ishida-Yamamoto A, Takahashi $H$, lizuka $H$ : Nuclear localization of beta-catenin in the hair matrix cells and differentiated keratinocytes. J Dermatol Sci 200I, 27(3): I70-I77.

37. Zhu AJ, Watt FM: beta-catenin signaling modulates proliferative potential of human epidermal keratinocytes independently of intercellular adhesion. Development 1999, I 26( I 0):2285-2298.

38. Fathke C, Wilson L, Shah K, Kim B, Hocking A, Moon R, Isik F: Wnt signaling induces epithelial differentiation during cutaneous wound healing. BMC Cell Biol 2006, 7:4.

39. Vaporciyan AA, DeLisser HM, Yan HC, Mendiguren II, Thom SR, Jones ML, Ward PA, Albelda SM: Involvement of plateletendothelial cell adhesion molecule-I in neutrophil recruitment in vivo. Science 1993, 262(5 I39): $1580-1582$.

40. Galeano M, Altavilla D, Cucinotta D, Russo GT, Calo M, Bitto A Marini H, Marini R, Adamo EB, Seminara P, Minutoli L, Torre V, Squadrito F: Recombinant human erythropoietin stimulates angiogenesis and wound healing in the genetically diabetic mouse. Diabetes 2004, 53(9):2509-25I7.

4I. Lévesque V, Fayad T, Ndiaye K, Nahe Diouf M, Lussier JG: Sizeselection of cDNA librairies for the cloning of cDNAs after suppression subtractive hybridization. Biotechniques 2003, 35:72-78.

42. [http://www.ncbi.nlm.nih.gov/BLAST/]

43. Bédard J, Brûlé S, Price CA, Silversides DW, Lussier JG: Serine protease inhibitor-E2 (SERPINE2) is differentially expressed in granulosa cells of dominant follicle in cattle. Mol Reprod Dev 2003, 64:152-165

44. Ndiaye K, Fayad T, Silversides DW, Sirois J, Lussier JG: Identification of downregulated messenger RNAs in bovine granulosa 
cells of dominant follicles following stimulation with human chorionic gonadotropin. Biol Reprod 2005, 73:324-333.

45. [http://rsb.info.nih.gov/nih-image/].

46. Bradford MM: A rapid and sensitive method for the quantitation of microgram quantities of protein utilizing the principle of protein-dye binding. Anal Biochem 1976, 7:248-254.

47. Brûlé S, Faure R, Dore M, Silversides DW, Lussier JG: Immunolocalization of vacuolar system-associated protein-60 (VASAP-60). Histochem Cell Biol 2003, I I 9:37I-38I.

Publish with Bio Med Central and every scientist can read your work free of charge

"BioMed Central will be the most significant development for disseminating the results of biomedical research in our lifetime. " Sir Paul Nurse, Cancer Research UK

Your research papers will be:

- available free of charge to the entire biomedical community

- peer reviewed and published immediately upon acceptance

- cited in PubMed and archived on PubMed Central

- yours - you keep the copyright

Submit your manuscript here:

http://www.biomedcentral.com/info/publishing_adv.asp
BioMedcentral 